\title{
Spectroscopic Fourier Transform Infrared Study of Poly (N-Isopropylacrylamide)-Human Recombinant Platelet- Derived Growth Factor- BB Protein as a Strategic Biobetter Regenerative Material
}

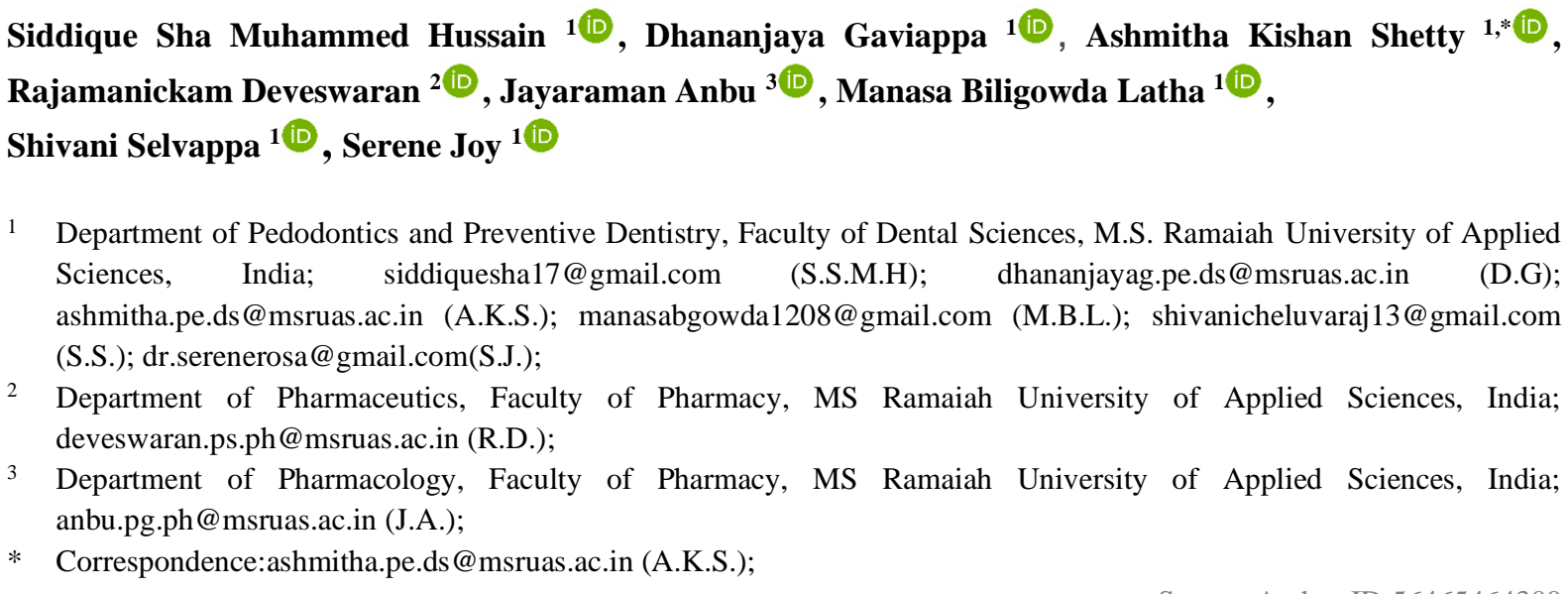

Received: 20.04.2021; Revised: 20.07.2021; Accepted: 25.07.2021; Published: 12.09.2021

\begin{abstract}
Biobetter or Biosuperior are recombinant protein drugs with one or more characteristics that are better than the original formulation. Platelet-Derived Growth Factor (PDGF) is a potent mitogen that can induce pulp stem cell proliferation and promote angiogenesis in vitro. PDGF-BB is required for wound healing, and they are chemoattractants that can activate macrophages and fibroblast activation in vitro. Poly(n-isopropylacrylamide) (PNIPAM) polymer is a thermoresponsive polymer widely used for drug delivery. A lyophilized combination of PNIPAM and $5 \mu \mathrm{g}$ of Recombinant Human PDGF-BB(rhPDGF-BB)(sigma Aldrich-P3201) protein was prepared in the present study. This combination was subjected to Spectroscopic Fourier-Transform Infrared(FTIR) study. The results suggested that a biophysical approach like FTIR enables assessing protein stability and aggregation tendency of recombinant proteins, contributing as a useful method to identify samples with prospective high therapeutic values.
\end{abstract}

Keywords: Platelet-Derived Growth Factor; thermoresponsive polymer; Fourier-Transform Infrared Spectroscopy.

(C) 2021 by the authors. This article is an open-access article distributed under the terms and conditions of the Creative Commons Attribution (CC BY) license (https://creativecommons.org/licenses/by/4.0/).

\section{Introduction}

The dental pulp tissue has the capacity to undergo repair and also regenerate. This occurs due to any local irritants that cause inflammation and stimulate Human Dental Pulp Stem Cells (HDPSC) to drift to the site of injury, where they consequently undergo differentiation into odontoblasts due to the presence of growth factors [1]. Direct pulp capping is a therapy aiming to preserve the tooth's vitality by assisting pulp repair and induces dentin formation. This concept is centered on the perception that dental pulp inherently has potential for tissue repair, resulting in reparative dentin formation. Direct pulp capping is indicated to 
avoid or delay the need for a root canal treatment, mainly with young or immature teeth. Certain materials have been used as pulp capping for almost two decades. One such material is Mineral Trioxide Aggregate (MTA) which is considered the gold standard for direct pulp capping procedures[2]. MTA has disadvantages like long setting time, difficulty to manipulate, and can not exclusively induce dentinogenesis. Hence new biomaterials are required for pulp capping[3].

Growth Factors(GF)can direct the fate of cells and play a crucial role in tissue engineering. Research is being made to explore growth factor delivery strategies[4]. GF are vital components essential for tissue engineering since they serve as signaling molecules between the cells. Research is ongoing to develop dental biomaterials and scaffolds augmented with single or combined active bio-molecules to induce dentin and pulp regeneration[5].

The introduction of recombinant Growth Factor (rhGF) as a routine therapeutic agent in medical practice is limited. The American Food and Drug Administration (FDA) has allowed recombinant Platelet-derived Growth Factor(rhPDGF) clinical use. To the best of our knowledge, it is the first recombinant growth factor to be allowed [6].

The short half-life of PDGF administration is a disadvantage. Even though clinical studies on the development of neoplasms following the application of rhGF are scarce, increased concentrations of exogenous GF applied in tissues pose a risk of undesirable side effects. Because of the short half-life of PDGF, biomaterials capable of forming a depot have been created[7].

PDGF was initially identified in platelets, and the PDGF family includes 5 polypeptides or isoforms: PDGF-AA, PDGF-AB, PDGF-BB, PDGF-CC, and PDGF-DD. Amongst these isoforms, PDGF-BB is a unique ligand that can interact with all 3 PDGF receptors: PDGF-AA, PDGF-AB, and PDGF-BB. PDGF-BB is a compelling mitogenic factor and has been acknowledged as the chief mediator in wound healing and tissue repair. In addition to this, PDGF-BB also indirectly promotes angiogenesis by promoting Vascular Endothelial Growth Factor (VEGF) secretion. It also has an important role in the stabilization of newly formed blood vessels. PDGF-BB can facilitate osteogenic differentiation by acting on Bone Marrow Stem Cells (BMSCs) in a dose-dependent mode and hence, has been extensively used in medicine for bone regeneration. PDGF-BB is also a dominant chemo-attractive agent for Mesenchymal Stem Cells (MSCs). Although studies have reported that PDGF-BB can promote tissue regeneration via the recruitment of stem cells, the exact mechanism and actions of PDGF-BB that contribute to HDPSCs mediated dentin-pulp complex regeneration remains unclear[8].

The use of rhPDGF-BB is being considered a treatment for numerous musculoskeletal indications due to its biological properties. In bone homeostasis, repair, and regeneration, rhPDGF-BB is an important regulatory molecule. It upregulates essential cytokines for osseous and soft-tissue healing and regeneration, and it is chemotactic and mitogenic for osteoblasts and undifferentiated osteoprogenitor cells. The rhPDGF-BB tends to be safe and efficient in improving the repair of musculoskeletal and maxillofacial disorders, based on convincing data from preclinical studies and an increasing number of clinical investigations. The FDA has approved GEM 21S (Johnson and Johnson Wound Management-Ethicon, Somerville, New Jersey) and Regranex (Johnson and Johnson Wound Management-Ethicon, Somerville, New Jersey), an rhPDGF-BB-containing formulation for repeat topical application to treat nonhealing lower extremity diabetic ulcers. Furthermore, the biology of PDGF suggests that it may have significant musculoskeletal clinical benefits for patients with impaired wound 
healing, such as those with diabetes mellitus, which will benefit significantly from the induction and proliferation of osteoprogenitor and other forms of reparative cells [9].

The term Biobetter or Biosuperior refers to a recombinant protein drug that belongs to the same class but is not identical to an existing biopharmaceutical and has improved properties over the original[10]. A Biobetter compound was synthesized in this study by incorporating a smart polymer, PNIPAM, into human rhPDGF-BB. PNIPAM is a thermoresponsive polymer that can be synthesized from monomers through free radical polymerization, and it is easily functionalized, making it available in wide fields. PNIPAM shows invertible changes in hydrated and dehydrated forms under temperature variations and exhibits Lower Critical Solution Temperature (LCST) at around $31^{\circ} \mathrm{C}$ in aqueous solutions, close to the physiological threshold. The versatility of PNIPAM has enabled its use in cell culture, tissue engineering, enzymatic immobilization, drug delivery, wound dressing, biosensors [11].

The main aim of vital pulp therapy is to maintain the remaining pulp's vitality and initiate the pulp regeneration at the pulp-dentin complex. An ideal biomaterial for vital pulp therapy should provide an excellent seal against bacteria; it should not generate an acute inflammatory response. It should assist in the induction of osteoblastic differentiation and proliferation for pulp regeneration. Therefore, biocompatibility and cytotoxicity must be fully evaluated before using a novel material as a pulp-capping agent[12].

Hence, the study aimed to synthesize a Biobetter using rhPDGF-BB and PNIPAM and subject it to FTIR analysis.

\section{Materials and Methods}

The rhPDGF-BB was procured from Sigma Aldrich(P3201 - Platelet-Derived Growth Factor-BB human). $5 \mu \mathrm{g}$ was transferred into an Eppendorf tube using a $2 \mathrm{ml}$ syringe.PNIPAM was procured from Thermo Fisher (AC412780250 SDS). About $60 \mathrm{mg}$ of PNIPAM was added in a divided concentration of $20 \mathrm{mg}$ into the Eppendorf containing PDGF-BB. After the polymer addition, the combination was subjected to vigorous mixing using a Magnetic stirrer until a clear homogenous mix was obtained for each divided concentration of the polymer. The final obtained mixture was about $0.5 \mathrm{ml}$ in a liquid form, clear in color. The mixture was subjected to lyophilization. The final Biobetter obtained was about $30 \mathrm{mg}$ maintained at $-20^{\circ} \mathrm{C}$ until further analysis.

\subsection{FTIR analysis.}

The Biobetter and PNIPAM were subjected to FTIR analysis for determining the Infrared Spectroscopy of the sample using FTIR - 8400S(Shimadzu Scientific Instruments Inc.) instrument. The 1/100 part of the sample was mixed with potassium bromide $(\mathrm{KBr})$ in a mortar and pestle and made into the refined homogenous mix. It was later transferred into a pellet and placed in the analyzing compartment. The samples were subjected to an infrared spectrum of $7800 \mathrm{~cm}-1$ to $350 \mathrm{~cm}-1$. A32-bit high-performance (IR solution) FTIR software was used to assess the result. The peaks obtained were smoothened in the software.

\section{Results and Discussion}

\subsection{Results of PNIPAM-rhPDGF-BB.}

The FTIR spectra of Biobetter ranged from $2852 \mathrm{~cm}^{-1}-3346 \mathrm{~cm}^{-1}$ shown in Figure 1.The peaks obtained in the analysis are shown in Table 1.The various peaks obtained are 
$418.52 \mathrm{~cm}^{-1}, 1245.93 \mathrm{~cm}^{-1}, 1282.57 \mathrm{~cm}^{-1}, 1442.66 \mathrm{~cm}^{-1}, 1558.38 \mathrm{~cm}^{-1}, 1610.45 \mathrm{~cm}^{-1}, 1745.46$ $\mathrm{cm}^{-1}, 2852.52 \mathrm{~cm}^{-1}, 2921.96 \mathrm{~cm}^{-1}$ and $3346.27 \mathrm{~cm}^{-1}$. The peak $2921.96 \mathrm{~cm}^{-1}$ showed the maximum corrected peak height of 2.808 with a corrected area coverage of 0.506 depicting the presence of $\mathrm{C}-\mathrm{H}$ alkane(stretch) followed by $1558.38 \mathrm{~cm}^{-1}$ showing the second maximum corrected peak height of 3.863 covering a corrected area of 0.344 corresponded to $\mathrm{N}-\mathrm{H}$ primary and secondary amines and amides (stretch). The peak $2852.52 \mathrm{~cm}^{-1}$ with a corrected peak height of 1.624 with an area coverage of 0.163 also depicted the presence of $\mathrm{C}-\mathrm{H}$ alkane (stretch). $1610.45 \mathrm{~cm}^{-1}$ with a corrected peak height of 1.238 and corrected area coverage of 0.161 confirmed the presence of $\mathrm{C}=\mathrm{C}$ alkene. The peaks $1282.57 \mathrm{~cm}^{-1}$ and $1245.93 \mathrm{~cm}^{-1}$ with a corrected peak height of 0.701 and 0.164 and corrected area coverage of 0.336 and 0.194 correspond to $\mathrm{S}=\mathrm{O}$ sulfones, Sulfonyl Chloride, Sulfonamides, and Sulfates. The peak 3346.27 $\mathrm{cm}^{-1}$ with a corrected peak height of 0.124 and corrected area coverage of 0.01 depicts the presence of H-O carboxylic acid.

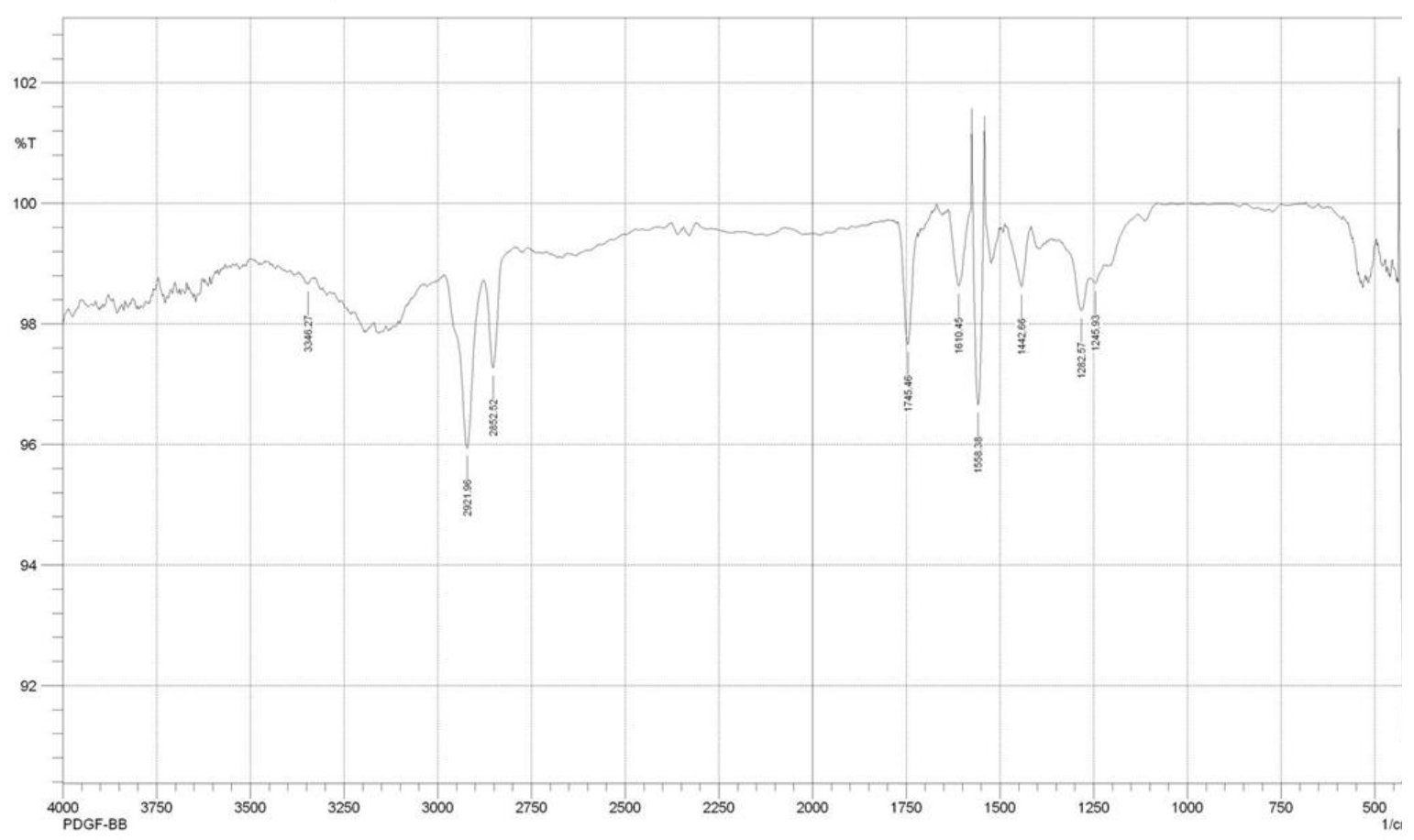

Figure 1. FTIR spectra of Biobetter ranging from $2852 \mathrm{~cm}^{-1}-3346 \mathrm{~cm}^{-1}$.

Table 1. Values of the peak obtained using FTIR analysis.

\begin{tabular}{l|l|l|l|l|l|l|l} 
& Peak & Height & Corr.Height & Base $(\mathrm{H})$ & Base $(\mathrm{L})$ & Area & Corr.Area \\
\hline 1 & 418.52 & 9.044 & 8.949 & 433.95 & 403.09 & 0.841 & 0.831 \\
\hline 2 & 1245.93 & 1.327 & 0.164 & 1259.43 & 1222.79 & 0.194 & 0.013 \\
\hline 3 & 1282.57 & 1.779 & 0.701 & 1319.22 & 1261.36 & 0.336 & 0.077 \\
\hline 4 & 1442.66 & 1.384 & 0.971 & 1479.3 & 1419.51 & 0.233 & 0.126 \\
\hline 5 & 1558.38 & 3.351 & 3.863 & 1573.81 & 1542.95 & 0.276 & 0.344 \\
\hline 6 & 1610.45 & 1.371 & 1.238 & 1637.45 & 1581.52 & 0.194 & 0.161 \\
\hline 8 & 1745.46 & 2.333 & 1.878 & 1770.53 & 1722.31 & 0.285 & 0.19 \\
\hline 9 & 2852.52 & 2.731 & 1.624 & 2877.6 & 2794.66 & 0.518 & 0.163 \\
\hline 10 & 2921.96 & 4.056 & 2.808 & 2981.74 & 2879.52 & 1.06 & 0.506 \\
\hline
\end{tabular}

\subsection{Result of PNIPAM.}

The FTIR spectra of PNIPAM ranged from $808.12 \mathrm{~cm}^{-1}-3296.12 \mathrm{~cm}^{-1}$ showed in figure 2. The longest peak obtained was $1533.30 \mathrm{~cm}^{-1}$ corresponding toN=O nitro compound, and the peaks $1367.44 \mathrm{~cm}^{-1}, 1413.72 \mathrm{~cm}^{-1}$, and $1452.30 \mathrm{~cm}^{-1}$ also corresponded the same. The secondlongest peak was $2970.17 \mathrm{~cm}^{-1}$ depicting the presence of $\mathrm{O}-\mathrm{H}$ carboxylic acid. The other peaks 
were $808.12 \mathrm{~cm}^{-1}, 846.69 \mathrm{~cm}^{-1}, 918.05 \mathrm{~cm}^{-1}, 964.34 \mathrm{~cm}^{-1}$ and $989.41 \mathrm{~cm}^{-1}$ indicating the presence of $\mathrm{C}-\mathrm{H}$ alkenes. The peaks at $1064.63 \mathrm{~cm}^{-1}, 1128.28 \mathrm{~cm}^{-1}$, and $1170.71 \mathrm{~cm}^{-1}$ represented C-O alcohols,esters,carboxylic acids, anhydrates, etc.The peaks at $1245.93 \mathrm{~cm}^{-1}, 1325.01 \mathrm{~cm}^{-1}$, and $1306.72 \mathrm{~cm}^{-1}$ confirmed the C-N amine compound in the PNIPAM. The peak at $2875.67 \mathrm{~cm}^{-1}$, $3072.39 \mathrm{~cm}^{-1}$, and $2935.46 \mathrm{~cm}^{-1}$ showed the presence of $\mathrm{C}-\mathrm{H}$ aldehyde, $\mathrm{C}-\mathrm{H}$ alkene, and C-H alkane respectively. The peaks $1604.66 \mathrm{~cm}^{-1}, 3284.55 \mathrm{~cm}^{-1}$ and $3296.12 \mathrm{~cm}^{-1}$ indicate N-H primary and secondary amines and amides.

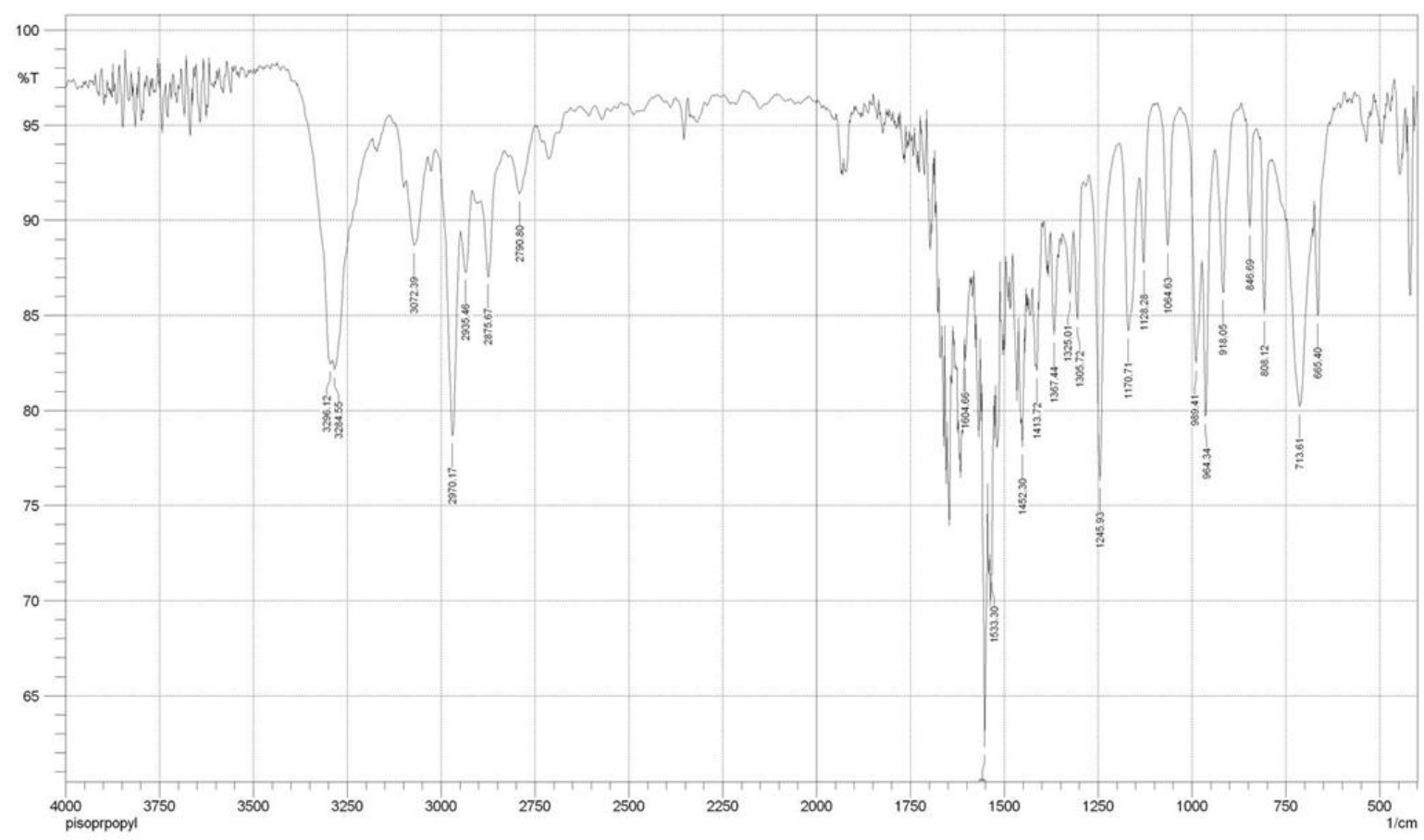

Figure 2. FTIR spectra of PNIPAM ranging from $808.12 \mathrm{~cm}^{-1}-3296.12 \mathrm{~cm}^{-1}$.

Therapeutic protein drugs are a form of medication that supports patients in great need of new therapies. Cancers, autoimmunity/inflammation, infectious agent exposure, and genetic defects are among the clinical conditions for which recombinant protein therapeutics have recently been approved[13].In this study, we have attempted to formulate a recombinant protein, a Biobetter, to be used to treat direct pulp therapy.

Pulp-dentin tissue regeneration can be facilitated by applying PDGF-BB by its influence on dental pulp stem cells. The PDGF-BB can induce odontoblastic differentiation via gene upregulation. It may be due to 1)inducing dentinogenesis by dentin sialophoshoprotein, 2) regulating the gene transcription of dentin matrix protein-1 during early odontoblast differentiation, and 3) dentin mineralization with calcium phosphate and early differentiation by alkaline phosphatase[14].

PNIPAM is a popular thermosensitive polymer that has attracted a lot of research interest[15]. PNIPAM is one of the most meticulously researched synthetic polymers for applications such as controlled drug delivery, cell-sheet engineering, biosensors, and tissue engineering[16].It has a wide range of biomedical applications due to its unique properties, and we incorporated PNIPAM in our Biobetter.

The FTIR spectra of PNIPAM showed expected bands at $3500-3200 \mathrm{~cm}^{-1}, 1600$ and $1500 \mathrm{~cm}^{-1}$, and 2800 and $1400 \mathrm{~cm}^{-1}$ related to $\mathrm{N}-\mathrm{H}, \mathrm{C}=\mathrm{O}$, and $\mathrm{C}-\mathrm{H}$ bonding, respectively found in other studies, which were similar to results obtained in our study[17].

The FTIR analysis of Biodentine, a well-known pulp regenerative material, showed bands at $3567.7 \mathrm{~cm}^{-1}$ and $3426 \mathrm{~cm}^{-1}$ correspondings to groups-H. Also, it showed the presence 
of methylene group at $2925 \mathrm{~cm}^{-1}$, carboxylic acid $\mathrm{C}=\mathrm{O}$ at $1739 \mathrm{~cm}^{-1}$, and aromatic ring or a secondary amine at $1620 \mathrm{~cm}^{-1}[18]$. These results matched with the FTIR spectra of Biobetter.

Wound healing via regulation of anti-inflammatory and cytokine secretion using polydopamine-assisted PDGF-BB immobilization on poly[(rac-lactide)-co-glycolide] (PLGA) fibrous substrate when subjected to FTIR yielded similar peaks at $1596 \mathrm{~cm}^{-1}$ depicting the presence of characteristic amide I and amide II of PDGF-BB[19]. Analysis of Biobetter also showed similar peaks.

FT-IR spectrum of the PNIPAM microgel showed different peaks at different locations for different functional groups. C-H asymmetric stretching $\left(2970 \mathrm{~cm}^{-1}\right), \mathrm{C}-\mathrm{H}$ symmetric stretching $\left(2874 \mathrm{~cm}^{-1}\right), \mathrm{C}=\mathrm{O}$ amide group $\left(1634 \mathrm{~cm}^{-1}\right), \mathrm{N}-\mathrm{H}$ bending $\left(1540 \mathrm{~cm}^{-1}\right), \mathrm{C}-\mathrm{N}$ stretching $\left(1366 \mathrm{~cm}^{-1}\right),-\mathrm{CH}_{2}$ - and $-\mathrm{CH}_{3}$ bending vibrations are all notable peaks (1460 and $1386 \mathrm{~cm}^{-1}$ respectively)[20]. These peaks are similar to the PNIPAM, FTIR spectra obtained in our study.

Also, to our knowledge, this is the first study applying FTIR to PDGF-BB in combination with PNIPAM. The result demonstrated that the presence of alkene, alkane, sulfonyl chloride, sulfanes, sulfonamide, and carboxylic acids, which implies the chemical structure of PDGF-BB is still present in Biobetter, concluding that the lyophilized powder retained its regenerative properties.

\section{Conclusions}

Our study concluded that the combination of PNIPAM and PDGF-BB was significantly positive in retaining its chemical properties. Hence, it can be emphasized that the combination can efficiently be used as a direct pulp capping agent, the disadvantages of existing pulp capping agents. A more conclusive result would require further characterization of the Biobetter combination.

\section{Funding}

This study received no external funding.

\section{Acknowledgments}

We acknowledge the Faculty of Pharmacy, M S Ramaiah University of Applied Sciences, for helping in the execution of the study.

\section{Conflicts of Interest}

The authors declare no conflict of interest.

\section{References}

1. Shah, D.; Lynd, T.; Ho, D.; Chen, J.; Vines, J.; Jung, H.-D.; Kim, J.-H.; Zhang, P.; Wu, H.; Jun, H.-W. PulpDentin Tissue Healing Response: A Discussion of Current Biomedical Approaches. Journal of clinical medicine 2020, 9, 434, https://doi.org/10.3390/jcm9020434.

2. Bui, A.H.; Van Pham, K. Evaluation of Reparative Dentine Bridge Formation after Direct Pulp Capping with Biodentine. Journal of International Society of Preventive \& Community Dentistry 2021, 11, 77, https://doi.org/10.4103/jispcd.JISPCD_390_20.

3. Al-Sabri, F.A.; El-Marakby, A.M.; Qaid, N.M. Role of Mineral Trioxide Aggregate (MTA) and Calcium Hydroxide in Conservative Dentistry as Pulp Capping Material: A Review. American Journal of Health Research 2017, 5, 1-6, https://doi.org/10.11648/j.ajhr.20170501.11. 
4. Aguilar, L.M.C.; Silva, S.M.; Moulton, S.E. Growth Factor Delivery: Defining the next Generation Platforms for Tissue Engineering. Journal of Controlled Release 2019, 306, 4058,https://doi.org/10.1016/j.jconrel.2019.05.028.

5. Wongkhum, C.; Chotigeat, W.; Kedjarune-Leggat, U. Effect of Recombinant Vascular Endothelial Growth Factor and Translationally Controlled Tumor Protein on 2-Hydroxyethyl Methacrylate-Treated Pulp Cells. Molecular medicine reports 2018, 17, 6100-6108, https://doi.org/10.3892/mmr.2018.8593.

6. Wieman, T.J.; Smiell, J.M.; Su, Y. Efficacy and Safely of a Topical Gel Formulation of Recombinant Human Platelet-Derived Growth Factor-BB (Becaplermin) in Patients with Chronic Neuropathic Diabetic Ulcers: A Phase III Randomized Placebo-Controlled Double-Blind Study. Diabetes care 1998, 21, 822-827, https://doi.org/10.2337/diacare.21.5.822.

7. Roy, K.; Mao, H.-Q.; Huang, S.-K.; Leong, K.W. Oral Gene Delivery with Chitosan-DNA Nanoparticles Generates Immunologic Protection in a Murine Model of Peanut Allergy. Nature medicine 1999, 5, 387-391, https://doi.org/10.1038/7385.

8. Zhang, M.; Yu, W.; Niibe, K.; Zhang, W.; Egusa, H.; Tang, T.; Jiang, X. The Effects of Platelet-Derived Growth Factor-BB on Bone Marrow Stromal Cell-Mediated Vascularized Bone Regeneration. Stem Cells International 2018, 2018, e3272098, https://doi.org/10.1155/2018/3272098.

9. Hollinger, J.O.; Hart, C.E.; Hirsch, S.N.; Lynch, S.; Friedlaender, G.E. Recombinant Human Platelet-Derived Growth Factor: Biology and Clinical Applications. JBJS 2008, 90, 48-54, https://doi.org/10.2106/JBJS.G.01231.

10. Sandeep, V.; Parveen, J.; Chauhan, P. Biobetters: The Better Biologics and Their Regulatory Overview. Int J Drug Regul Aff 2016, 4, 13-20, https://doi.org/10.22270/ijdra.v4i1.177.

11. Yang, L.; Fan, X.; Zhang, J.; Ju, J. Preparation and Characterization of Thermoresponsive Poly (NIsopropylacrylamide) for Cell Culture Applications. Polymers 2020, 12, 389, https://doi.org/10.3390/polym12020389.

12. Dou, L.; Yan, Q.; Yang, D. Effect of Five Dental Pulp Capping Agents on Cell Proliferation, Viability, Apoptosis and Mineralization of Human Dental Pulp Cells. Experimental and therapeutic medicine 2020, 19, 2377-2383, https://doi.org/10.3892/etm.2020.8444.

13. Lagassé, H.D.; Alexaki, A.; Simhadri, V.L.; Katagiri, N.H.; Jankowski, W.; Sauna, Z.E.; Kimchi-Sarfaty, C. Recent Advances in (Therapeutic Protein) Drug Development. Flo00Research 2017, 6, https://dx.doi.org/10.12688\%2Ff1000research.9970.1.

14. Zhang, M.; Jiang, F.; Zhang, X.; Wang, S.; Jin, Y.; Zhang, W.; Jiang, X. The Effects of Platelet-Derived Growth Factor-BB on Human Dental Pulp Stem Cells Mediated Dentin-Pulp Complex Regeneration. Stem cells translational medicine 2017, 6, 2126-2134, https://doi.org/10.1002/sctm.17-0033.

15. Xu, X.; Liu, Y.; Fu, W.; Yao, M.; Ding, Z.; Xuan, J.; Li, D.; Wang, S.; Xia, Y.; Cao, M. Poly (NIsopropylacrylamide)-Based Thermoresponsive Composite Hydrogels for Biomedical Applications. Polymers 2020, 12, 580, https://doi.org/10.3390/polym12030580.

16. Spasojević, M.; Vorenkamp, J.; Jansen, M.R.; De Vos, P.; Schouten, A.J. Synthesis and Phase Behavior of Poly (N-Isopropylacrylamide)-b-Poly (L-Lysine Hydrochloride) and Poly (N-Isopropylacrylamide-CoAcrylamide)-b-Poly (L-Lysine Hydrochloride). Materials 2014, 7, 5305-5326, https://doi.org/10.3390/ma7075305.

17. Roach, P.; McGarvey, D.J.; Lees, M.R.; Hoskins, C. Remotely Triggered Scaffolds for Controlled Release of Pharmaceuticals. International journal of molecular sciences 2013, 14, 8585-8602, https://doi.org/10.3390/ijms14048585.

18. Rodríguez Rocha, A.C.; Hernández Padrón, G.; García Garduño, M.V.; García Aranda, R.L. Physicochemical Analysis of MTA Angelus ${ }^{\circledR}$ and Biodentine ${ }^{\circledR}$ Conducted with X Ray Difraction, Dispersive Energy Spectrometry, X Ray Fl Uorescence, Scanning Electron Microscope and Infra Red Spectroscopy. Revista Odontológica Mexicana, http://dx.doi.org/10.1016/j.rodmex.2016.02.023.

19. Yang, X.; Zhan, P.; Wang, X.; Zhang, Q.; Zhang, Y.; Fan, H.; Li, R.; Zhang, M. Polydopamine-Assisted PDGF-BB Immobilization on PLGA Fibrous Substrate Enhances Wound Healing via Regulating AntiInflammatory and Cytokine Secretion. PloS one 2020, 15, e0239366, https://doi.org/10.1371/journal.pone.0239366.

20. Shah, L.A.; Farooqi, Z.H.; Naeem, H.; Shah, S.M.; Siddiq, M. Synthesis and Characterization of Poly (NIsopropylacrylamide) Hybrid Microgels with Different Cross-Linker Contents. J Chem Soc Pak 2013, 35 , 1522-1529, https://doi.org/10.1007/s11356-020-09145-w. 